\title{
JOSÉ RUIBAL Y SU MAJESTAD LA SOTA [1966]: LAS POLÍTICAS FRANQUISTAS Y EL PROCESO SUCESORIO COMO UN TUTE DE LA BARAJA ESPAÑOLA ${ }^{1}$
}

\author{
JOSÉ RUIBAL AND SU MAJESTAD LA SOTA [1966]: FRANCOIST POLITICS \\ AND THE SUCCESSION PROCESS AS A SPANISH DECK OF CARDS'S TUTE
}

\author{
Alejandro COELLO HERNÁNDEZ \\ Instituto de Historia, CSIC \\ alejandro.coello@cchs.csic.es
}

\begin{abstract}
Resumen: Su Majestad la Sota [1966], de José Ruibal, pasó por censura en 1970 para ser representada, aunque fue finalmente prohibida a tan solo dos días de su estreno. Sin embargo, debido a este expediente de censura, se conserva el único ejemplar hasta ahora localizado. En el mecanoscrito, se pueden rastrear las relaciones entre la obra dramática y el régimen franquista, en especial con el proceso de sucesión que no se resolvió hasta 1969. Este trabajo pretende contextualizar el olvido en que ha caído esta pieza de Ruibal y analizar las correspondencias entre la realidad política y la construcción alegórica que realiza Ruibal a partir de la baraja española.
\end{abstract}

Palabras clave: José Ruibal. Su Majestad la Sota. Franquismo. Política. Teatro. Censura.

\begin{abstract}
José Ruibal's Su Majestad la Sota [1966] was sent to the censorship for evaluation in 1970 and was not granted permission for its performance just two days before the opening night. However, the only known copy to date of this play has been preserved thanks to the censorship file, as it includes a typewritten version. The reading of this manuscript shows a series of references to the Francoist regime, particularly the succession of power, which was not cleared up until 1969. This paper aims to contextualize the oblivion this play has fallen into and to analyze the links between the Francoist political background and the interesting allegorical representation conceived by Ruibal, based on the traditional Spanish deck of cards.
\end{abstract}

Keywords: José Ruibal. Su Majestad la Sota. Francoism. Politic. Theatre. Censorship.

\footnotetext{
${ }^{1}$ Este artículo nace de la revisión y ampliación de los resultados de mi Trabajo de Fin de Máster (2018/2019) dirigido por Emilio Peral Vega, a quien agradezco enormemente su ayuda y confianza. Además, cuenta con una ayuda predoctoral del Ministerio de Ciencia e Innovación (FPU19/00203) y está realizado en el marco del proyecto de investigación P.E. I+D+i Tras los pasos de la Silfide. Una historia de la danza en España, 1836-1936 (ref. PGC2018-093710-A-I00), financiado por el Ministerio de Ciencia, Innovación y Universidades, la Agencia Estatal de Investigación y el Fondo Europeo de Desarrollo Regional de la Unión Europea.
} 


\section{INTRODUCCIÓN}

José Ruibal Argibay (Xeve, Pontevedra, 1925 - Cuenca, 1999) fue uno de los dramaturgos españoles integrantes de la neovanguardia o el Teatro Underground, según la denominación de George Wellwarth ${ }^{2}$. Su obra dramática, en una clara consonancia con la de Francisco Nieva y Luis Riaza, se caracteriza por la experimentación, la alegorización y un imaginario surrealizante que lo sitúan como uno de los mayores exponentes del teatro español de vanguardia de la segunda mitad del siglo XX. Sin embargo, su presencia en la escena ha quedado relegada a lo largo de la historia: primero por las Normas de Censura del franquismo y luego por el olvido que vino con la democracia. Según los datos que manejo hasta ahora, tan solo pueden señalarse cuatro estrenos profesionales en España de la dramaturgia ruibalesca: El hombre y la mosca programado en 1983 en el María Guerrero por la compañía Puerto Rican Traveling Theatre; La sociedad unidimensional en 1995 por Alcores, Unidad de Producción, con dirección de César de Vicente; la versión que realizó de La Celestina en 1995 para el Teatre Condal de Barcelona dirigida por Hermmann Bonnin; y Animalia en el Auditorio Gustavo Freire de Lugo. Parte de este teatro continúa inédito $\mathrm{y}$, hasta ahora, no se ha localizado, ni siquiera por sus familiares. Por esa razón, este breve estudio pretende rescatar una obra de la dramaturgia inédita de José Ruibal con el fin de analizarla a partir de la poca documentación conservada y de estudiarla de acuerdo con su contexto de escritura.

Su Majestad la Sota, fechada en 1966, se encuentra dentro de las dramaturgias ruibalescas que abordan la alegorización en torno al poder absoluto y su perpetuación desde una estética grotesca. Llama la atención que entre 1966 y 1969 haya concebido tres obras en las que se propone profundizar sobre estas temáticas políticas desde una forma dramática ritual y sobre alegorías cada vez más elaboradas, lo que convierte a esta triada en el núcleo más complejo de las obras dramáticas largas del dramaturgo que se conservan. Así pues, el ciclo comenzaría con el texto que analizo de 1966, continuaría con su magna obra El hombre y la mosca de 1968 y terminaría con La máquina de pedir

\footnotetext{
${ }^{2}$ Aún la historiografía teatral hispánica no ha definido profundamente esta heterogénea promoción con el fin de determinar la denominación más operativa que sirva de convención académica. Así pues, ha recibido marbetes relacionados con aspectos sociopolíticos (teatro silenciado, de alcantarilla, soterrado, antifranquista, maldito, desvinculado), con criterios estéticos (teatro de vanguardia, neovanguardia, teatro simbolista) o por su novedad (Nuevo Teatro, new wave, new generation). Aunque algunos resultan más acertados que otros, más vagos y vacíos de contenido, a mi parecer, resulta acertada la denominación que le dio en 1972 George E. Wellwarth en Spanish Underground Drama, primer estudio de conjunto. Entiéndase underground no en el sentido de 'censurado' que arguye el hispanista estadounidense, sino en el sentido de 'contracultural, marginal y contestatario' y en relación con las estéticas que de esta postura política se derivan. Como plantea el propio Ruibal, "las diferencias entre el underground americano y el español es que el nuestro es realmente subterráneo, mientras que el americano funcionaba libremente y su calidad underground era simplemente una actitud estética y de ruptura" (Samaniego, 1977). Así pues, cabe señalar que bajo Teatro Underground recogemos también las aportaciones de escenógrafos, directores, actores y compañías independientes, lo que supone una apertura del fenómeno que se aplica, erradamente, solo a la escritura teatral.
} 
de 1969. De esta manera, Ruibal parece formular su propia Trilogía del Poder dentro de lo que Isabelle Reck (2010: 61) ha denominado el "cycle du pouvoir" para referirse a las dramaturgias experimentales de esta época que comparten una similar propuesta estéticotemática, con ejemplos notables como El arquitecto y el emperador de Asiria, de Fernando Arrabal; Las hermanas de Búfalo Bill, de Manuel Martínez Mediero; El desván de los machos y el sótano de las hembras, de Luis Riaza; o Guadaña al resucitado, de Ramón Gil Novales.

Por eso, con este estudio se pretende constatar dos cuestiones que trazan, por lo general, las alegorías underground construidas por este heterogéneo grupo de dramaturgos. Por un lado, se debe evitar el reduccionismo categórico que considera que la mayoría de las obras underground están limitadas por su carácter local o por su imposibilidad de adquirir nuevos significados fuera de otra sociedad que no sea la franquista $^{3}$, aspecto que ha provocado, en parte, el olvido de este teatro y que se ha perpetuado en los acercamientos críticos. Por otro lado, no parece adecuado afirmar que la alegoría responde a un simple proceso de enmascaramiento de la realidad contra la que se escribe porque, como comentó el propio Ruibal, esta promoción dramática no habría continuado cultivando el simbolismo y la alegoría si su objetivo principal hubiese sido vencer la "rémora del pasado" que es la censura, pues muy pocas veces salieron airosos de ella (Gómez García, 1971: 13). Por tanto, no se utilizó para evitar la censura, sino como mecanismo estético que conecta con dramaturgias extranjeras como las de Samuel Beckett o Bertolt Brecht. Sin olvidar estos preceptos, me propongo analizar Su Majestad la Sota y sus mecanismos de construcción alegórica a partir de la baraja española y sus conexiones con las políticas franquistas que sirvieron de inspiración al dramaturgo.

Como bien apunta Feuillastre (2016b: 158), los autores underground "mediante un teatro simbolista, presentan ficciones del poder español críticas con un régimen que trata de perpetuarse, pero que está llamado a una extinción inevitable" y, por consiguiente, adquiere cierta lógica la advertencia de Isabelle Reck (2010: 84): "peut-être plus qu'aucun autre théâtre, le téâtre de ces auteurs est un téâtre qui ne peut se lire sans tenir compte de ce contexte historique". Como ya he señalado antes, es innegable la relación con el franquismo y sus expresiones de poder, mucho más en Su Majestad la Sota, pero ese precepto no excluye que este teatro pueda entenderse desde otras ópticas. Con voluntad de establecer un diálogo con el proceso de sucesión franquista, se ha decidido releer la pieza a través del desarrollo de la legislación y de las políticas del régimen, ya que, en otro orden de asuntos, también puede ser útil para dudar sobre la fecha de composición, para valorar la inclusión de correcciones en la única versión conservada o para plantear la capacidad premonitoria de esta abstracción.

\footnotetext{
${ }^{3}$ El propio Ruibal sirve como ejemplo: en el estreno de El hombre y la mosca en el Off-Broadway de Nueva York, la proximidad con Latinoamérica evocaba para el público las dictaduras americanas, por lo que la obra adquirió otro sentido independiente de la situación política española.
} 


\section{LOCALIZACIÓN DEL MANUSCRITO Y PROBLEMAS DE DATACIÓN}

La única versión que se conoce de Su Majestad la Sota es un documento a máquina conservado en el Archivo General de la Administración en Alcalá de Henares en la caja 73/9770, expediente 148/70, con la signatura (03)046.000 73/9770. En trabajos anteriores, Anne Laure Feuillastre (2016a) ya había señalado algunas obras inéditas del Teatro Underground que se localizan en el Archivo de Censura, entre las que se refiere a esta. Este breve estudio supone un listado fundamental que completa las aportaciones de Berta Muñoz Cáliz (2006). A falta de una edición, cito a partir del mecanoscrito señalado junto al expediente de censura.

La obra fue enviada a la Junta de Censura el 8 de abril de 1970 para su estreno en el III Congreso de Nuevo Teatro de Tarragona por el Teatro Universitario de Cámara de Barcelona el 30 de abril. Se emitieron dos dictámenes: el primero se fecha el 14 de abril y el segundo, el 28 de ese mismo mes, dos días antes del estreno, que trajo consigo un gran revuelo y, sobre todo, el enfado de la compañía ${ }^{4}$.

En cuanto a la datación, hay una gran diversidad de opiniones, ya que tan solo contamos con una versión que pudo ser revisada. Por ejemplo, críticos como Oliva (1989) o Zahareas (1997) indican que se fecha en 1965, año poco probable sobre todo si se tiene en cuenta que Ruibal, en su edición de El hombre y la mosca de 1977 en la editorial Espiral, señaló el año de 1966 como fecha de finalización y añadió que fue trazada y pensada en Buenos Aires, donde estuvo entre 1957 y 1960 aproximadamente, según Van der Naald (1981: 119). Este año de 1966 parece acertado, además, desde el punto de vista histórico, pues se aprobó la Ley de Prensa e Imprenta que encabezó el ministro Manuel Fraga Iribarne.

Aunque ningún crítico ha señalado la fecha de 1967, la versión que nos ha llegado puede que haya tenido cierta influencia de varios acontecimientos claves que acontecieron en este año: se pone en vigor la primera Ley Orgánica del régimen y Ruibal es despedido de la jefatura de prensa de la sección de política internacional del diario Arriba, dirigido por su amigo Manuel Blanco Tobío, por presunta conspiración contra el régimen en su estancia en el Río de la Plata. Estas circunstancias, como comentó el autor, derivaron en un creciente acoso policial, ya que cada vez que el dramaturgo salía y entraba

\footnotetext{
${ }^{4}$ En la revista Yorick se publicó un artículo sin autoría sobre el III Congreso de Nuevo Teatro de Tarragona, en donde se incluyó el siguiente comunicado del TUC, que contiene algunas imprecisiones en cuanto a la segunda fecha de censura: "Teníamos prevista la actuación en Tarragona para el jueves 30 de abril. La obra que llevábamos era Su Majestad la Sota, de José Ruibal. El 19 del mismo mes y con motivo de nuestra estancia en Madrid para representar Los Cenci en el Teatro Marquina, dentro de las sesiones del Nacional de Cámara y Ensayo, nos dijo la Federación organizadora del Congreso que la obra se había prohibido, pero que los proyectos no deberían interrumpirse dado que entre la censura y el autor iban a haber conversaciones para solucionar el problema prescindiendo de 'algunos personajes incómodos' de la obra. Creímos, ya que no se nos avisó más tarde de lo contrario, que el día 30 podríamos actuar, pero ante nuestra sorpresa e indignación, tres días antes del estreno nos enteramos - y porque telefoneamos a la Federación en Madrid - de que no teníamos permiso. No se nos dio ninguna otra explicación, aparte de alguna aclaración informal" (Anónimo, 1970: 48-49).
} 
al país era sometido a numerosos interrogatorios, lo que en parte originó la escritura de El hombre y la mosca en 1968 (Díez, 1983: 34).

Algunos investigadores, como Feuillastre (2016b), contemplan que la composición se produjo en 1969 cuando tuvo lugar el nombramiento de Juan Carlos I como príncipe de España. Esta idea parece poco probable a pesar de que el núcleo temático de la obra sea la perpetuación del régimen de la Sota en la persona de un rey, puesto que ya desde 1966 se había avivado el debate monárquico. Además, Ruibal no se interesó especialmente por configurar un personaje de fácil identificación, como sí ocurre en El hombre y la mosca en donde el Doble es trasunto de Carrero Blanco.

Aun así, desde el punto de vista de la recepción, los acontecimientos políticos de julio de 1969 fueron definitivos para su censura, pues se prohibió de acuerdo al artículo $10^{\circ} \mathrm{y}$ $17^{\circ} 2$ y 3 de las Normas de Censura que se aplicaron al teatro a partir de 1964 que aluden, respectivamente, al contenido erótico y a " $2^{\circ}$ los principios fundamentales del Estado, la dignidad nacional y la seguridad interior o exterior del país; $3^{\circ}$ la persona del Jefe del Estado" (Orden de 9 de febrero de 1963). Entre los diversos informes del expediente de censura, destaca en este sentido el de Federico Muelas: "en el momento actual, esta crítica de la monarquía nos parece poco adecuada pues más allá de lo dicho iría la [sic] traque intención del público, siempre a expectación de lo indecible".

En definitiva, resultan significativas las correspondencias que se establecen entre estos años y Su Majestad la Sota, por lo que cabría suponer que quizá la escritura de la obra se finalizara en 1966 con posteriores revisiones, entre las que se encontraría esta versión de 1970. Ruibal, como él mismo comentó en una entrevista (Siles, 1983: 31), era asiduo a la reescritura de una misma pieza en busca del mayor perfeccionamiento del entramado alegórico.

\section{SU MAJESTAD LA SOTA: LAS ALEGORÍAS Y LAS POLÍTICAS FRANQUISTAS}

Aunque Ruiz Ramón (1986: 532) consideró que Su Majestad la Sota era un pretexto para criticar el franquismo, destacó de esta obra "la palabra crítica, riquísima de alusiones celtibéricas, y el discurso satírico, pleno de humor negro en donde se fustiga una larga cadena de 'realidades' no menos hispanas". De esta manera, el estudioso confirma el punto de partida de nuestra tesis: por un lado, las relaciones con el régimen político y, por otro, la resignificación del imaginario español en torno a la baraja sobre la que se articula la dramaturgia. Este trabajo se centra en estudiar el entramado alegórico desde esta óptica para comprender el posible referente que tuvo Ruibal a la ahora de abstraerse en una obra que termina trascendiendo las fronteras españolas. Se trata, pues, de una primera interpretación al no existir ningún estudio pormenorizado de esta dramaturgia, que ha sido analizada sucintamente desde la concepción de la fábula en algunos estudios de conjunto. 
La obra comienza con una rueda de prensa en que se notifica la decisión de la Sota de buscar un rey para un trono que tiene, detrás de él, "un pasado glorioso" y, debajo, "unos 50 millones de pobres" ${ }^{5}$. Ruibal esboza, así, desde el comienzo el carácter distanciador que toma con respecto a la fábula, en tono burlesco y con algunas frivolidades efectistas que acentúan la desoladora situación de los países dominados por el poder absoluto, en última instancia, su propio país. Así pues, afirma la Sota, “después de $150^{6}$ años de trono vacío levamos hoy el ancla de nuestra continuidad histórica” con lo que el dramaturgo gallego deja clara su posición: la aspiración del sistema totalitario es perpetuarse en un afán de estatismo. Se intuye una clara correlación con la vía que proyectó el régimen franquista para su continuidad y que se cerró en 1969 con el nombramiento de Juan Carlos I como Príncipe de España después de veintidós años de la Ley de Sucesión y treinta del fin de la Guerra Civil. En este ambiente decadente de inacción que representa el país de la Sota, "nunca se vieron en tanto apuros los reyes de la baraja" ahogados en un cariz tabernario en el que Bastos se queja de la ciática, Copas del vino y Oros de haber sido desalojados de los casinos y realojados en las tascas. La "continuidad histórica" se formula como una necesidad porque el país mítico de la Sota parece haberse detenido en el tiempo y haber entrado en colapso hasta tal punto que ya los jóvenes no saben jugar a la baraja, por lo que se ha de instaurar de nuevo el juego de cartas. Al final de la obra, como es lógico, todos sabrán jugar inexorablemente a la baraja española, lo que indica el triunfo del sistema totalitario.

El entramado alegórico se presenta, por ello, como una verdadera pieza de orfebrería dentro de las dramaturgias ruibalescas, aunque no exenta de contradicciones. De esta manera, Ruibal dibuja un orden lingüístico que se aleja de la representación de la vida. Traza unos personajes alegóricos de carácter político que se mueven, en un juego constante con el público, entre los usos miméticos de lo que representan (esto es, la baraja) y los significados simbólicos que se les otorga a cada uno de los elementos. Así, crea una obra de difícil análisis debido a la complejidad del mundo de ficción creado y a la decisiva función del público, quienes cierran y concretan el significado.

\subsection{Lenguaje, simbología y referentes}

Sin duda, la eficacia de esta simbología a partir de la baraja se encuentra en los diálogos de los personajes que, conscientes de su condición de cartas, juegan con la polisemia de las palabras relacionadas (como baza, tute, timba, barajar, encartar). Algunos ejemplos de estos juegos retóricos se fundamentan en la anfibología al convivir varios significados a la vez y resultan cómicos al fundir en uno el plano alegórico y el plano mimético. Cuando los periodistas le dicen a la Princesa que la Sota está soltera, ella

\footnotetext{
${ }^{5}$ La paginación del mecanoscrito conservado en el Archivo de Censura resulta dudosa, por lo que se cita sin referencia a las páginas.

${ }^{6}$ Según el testimonio del propio autor, que recoge Zahareas (1997: 27): “Un país indeterminado está anclado en la historia porque hace 300 años se quedó sin cabeza, es decir, sin rey".
} 
responde "yo no juego a esa carta", esto es, ni es su opción ni literalmente desea jugar con esa figura de la baraja. Para exigir que comience el concurso, exclama el rey de Oros: "¡Hagan juego, señores, hagan juego!”; como si se tratase de una partida de cartas en un casino o en una "timbe [sic]" como apunta Matías con un tono despectivo, por lo que se acentúa la parodia de la política y el gobierno como un espectáculo, que engarza con la búsqueda de una nueva teatralidad que Cornago (2005) ha señalado como paradigma de la Modernidad en el teatro español.

Ante los problemas derivados de tener cuatro reyes para sentarse en un único trono, Copas sentencia con una duología que se acompaña de una imagen plástica muy clara: "conocemos las leyes del juego. ¿Que hay crisis? Paciencia y barajar... Ya habrá más suerte en la próxima baza"; en esta ocasión, la respuesta resulta ingeniosa en un contexto de mayor gravedad que se destensa por el manejo de las palabras. De igual interés parece la oración "si es copa, le encarto" que enuncia el rey de Copas en relación al palo de la Sota: "encartar" se entiende como 'incluir', pero también se puede advertir una suerte de calambur que evoca la serie fónica encanto, lo que demuestra la audacia del juego lingüístico en la escritura ruibalesca. Se reiteran así continuamente estos giros que potencian el humorismo provocado por la resignificación de las palabras relacionadas con los juegos de carta. El lector y el espectador entran, de esta manera, en una multiplicidad de interpretaciones hasta llegar al final con la ceremonia festiva del "tute de reyes", que se comentará posteriormente. Esta continua búsqueda del lenguaje polisémico fortalece la denominación de Su Majestad la Sota como un "texto-fiesta" que formula Reck (2010: 67 ), en donde todo el ritual grotesco se convierte en un juego, acentuando la profunda tragedia que late en el fondo de la obra.

Debe señalarse en relación con lo comentado en la introducción que Ruibal sí tenía una clara intención de evocar el franquismo, aunque su propuesta al ser alegórica tiende tanto a la universalización como a la encriptación. Así pues, no resulta difícil identificar a Franco con la Sota porque Ruibal, incluso, le transfiere algunas de las actividades de su gusto, como la caza. Por ejemplo, el Periodista 1 insiste en que "Yo le regalaré esta pistola. ¿O ya tiene otro hobby? ¿Cuál es su arma favorita?”. Además, se pueden rastrear menciones de todo tipo, como al lema franquista "una, grande y libre" bajo el "piedra y unidad, unidad también de piedra". O se introducen referencias a canciones militares y del régimen, en este caso satirizaciones del canto legionario "El novio de la muerte" o del himno "Cara al sol" de la Falange Española de las JONS en las palabras del rey de Copas “AArriba, copas, a vencer!”. Como advierte Alberto Miralles (1977: 165), en el Teatro Underground "no se concibe a la legión sin sus recios 'novios de la muerte', ni a un servicio militar sin marchosos 'adoradores de Margarita y Madelones'. El 'Cara al Sol' hoy día no es solo una canción es una toma de partido". No obstante, Ruibal no introduce versiones satíricas ni música, sino soterradas menciones dentro de los diálogos a este imaginario artístico del régimen. No menos elocuente resulta que el portavoz de la Sota, que permanece ausente durante la primera mitad de la obra, se llame Matías. Este nombre evoca al periodista Matías Prats Cañete, quien puso voz a Noticiarios y Documentales 
(NO-DO). Asimismo, fue un reconocido comentarista deportivo como el personaje que, en un momento de tensión dramática, radia la decisión del árbitro suizo en torno a qué rey debe ocupar el trono como si fuese un partido de fútbol, una nueva forma de teatralidad en consonancia con lo expuesto por Cornago (2005).

\subsection{Los personajes alegóricos y las políticas de la dictadura franquista}

A continuación, se analizan los personajes alegóricos a partir de las figuras de los reyes, que son los actantes que motivan la acción dramática en detrimento de otros recursos ruibalescos que la detienen. A partir del análisis de los cuatro reyes, se entiende mejor al resto de personajes por la relación que establecen con ellos, en donde intervienen la inversión de las jerarquías de la baraja o la oposición a otros juegos de cartas.

Adquiere un especial valor simbólico el uso de los reyes de la baraja porque, como ellos mismos comentan, "hoy por hoy somos las únicas testas coronadas sobre las que se puede levantar una monarquía popular, precisamente por ese aire de taberna que tenemos". Asimismo, se reafirman en la idea de que "nosotros somos de todas las patrias". Se convierten, entonces, en símbolo de la aquiescencia popular frente al régimen unilateral de la Sota, que, astuta, decide neutralizarlos en su sistema. Ruibal, quizá con gran certeza, sintetiza de esta forma la integración de las diversas ramificaciones ideológicas dentro del aparato gubernamental franquista.

Los reyes se corresponden con los cuatro palos de la baraja española: Espadas, Oros, Copas y Bastos. Estas cuatro alegorías personificadas configuran cuatro modos distintos de control y cuatro manifestaciones de poder. Según Elda Maria Philips (1984: 102), esta presencia del cuatro fortalece la idea de un poder universal al relacionarlo con el tetragrámaton, por lo que juntos simbolizan las letras hebreas para Dios. El sumatorio de los reyes representa el sistema totalitario que quiere fortalecer la Sota.

En primer lugar, el rey de Espadas se formula como trasunto del militarismo. Es el único que consigue que "los soldados se sientan en torno a la baraja". Plantea la muerte como medida política para el control demográfico y como mecanismo de terror que acaba con la rebelión y el surgimiento de ideologías contestatarias. Esta visión entronca con el régimen franquista que nace, precisamente, del alzamiento militar de 1936. Por eso, Espadas se jacta al afirmar que "una guerra bien dosificada es como el cuerno de la abundancia, ya que al mermar el rebaño de descontentos prospera la paz social". La paz es vista como una "hija de la muerte", con clara evocación a la canción legionaria. Se define a sí mismo como un nuevo Cid, como si personificara ese pasado glorioso que se utilizó en los discursos de la dictadura franquista. Propugna continuamente la ley marcial, lo que explica su excesivo moralismo con la Princesa y su contradictoria relación con la Sota, a quien es servil a la par que propone asesinarla para instaurar su propio orden en un acto de equiparación con la Sota. Ante la necesidad de recurrir a un árbitro para que solucione la situación del trono, Espadas insiste en que sea de nacionalidad germana en alusión al nazismo. 
En segundo lugar, el rey de Oros también se inscribe en una red semántica clara, relacionada con el poder financiero que se expresa con continuos aforismos insertos en el discurso. Por ejemplo, "si supieses física monetaria, sabrías que el oro no se hunde". Se fundamenta en la concepción del rey como alegoría de la corrupción de un sistema asentado en lo económico en detrimento de lo social bajo el lema "corrompe y vencerás" porque "bajo mi reinado haré tejer una amplia red de corrupción donde todo aquel que se estime a sí mismo se presentará voluntario para ser corrompido". De esta manera, aquella persona económicamente incorruptible se debe considerar ingobernable, pues se establece una correlación indisoluble entre dinero y docilidad. De hecho, este es uno de los temas de mayor preocupación en la producción ruibalesca en donde se reflexiona de manera recurrente sobre el capitalismo severo, como en Los mendigos, El asno o La máquina de pedir. Detrás de este personaje, se puede intuir una alusión a la tecnocracia, que fue ocupando un papel fundamental en el régimen franquista en los años sesenta hasta llegar a ocupar todos los ministerios en 1969, lo que se ha denominado historiográficamente como el gobierno "monocolor".

En tercer lugar, el rey de Copas se concibe como un trasunto del ocio como mecanismo de control que neutraliza la disidencia desde el propio pueblo y borra la memoria colectiva. Este último aspecto lo considero de vital importancia en la obra, puesto que el pueblo se representa en un Coro trágico que ve cómo su realidad cotidiana es ignorada. La estrategia de Copas de difundir el alcoholismo, la liberalidad o el ambiente festivo reducen la preocupación y ayudan a la evasión del pueblo tanto de sus vidas como del desarrollo político del país: "bajo mi mandato tendréis la ocasión de ver que la protesta, por fundada que esté, acabará sus días en el fondo de un vaso, como el mosquito más listo". El pensamiento político de Ruibal se filtra especialmente en este personaje que sintetiza, desde el punto de vista contrario al del autor, ideas que van más allá del propio núcleo temático de la obra, como, por ejemplo, la reflexión en torno a un posible escenario democrático en que "sería obra imperfecta si perdiéramos de vista que una democracia alcohólica, para llegar al fondo, ha de ser pornográfica". Por esa razón, al final, Copas decreta como "monumento nacional las tabernas", símbolo del conformismo político a través del entretenimiento.

Por último, el rey de Bastos se presenta como la alegoría regia más endeble, pues el referente parece poco evidente. Algunos críticos han señalado que alegoriza "el inmovilismo agrario" (Wellwarth, 1970: 55), "la fuerza bruta" (Phillips, 1984: 102) o "la represión policiaca” (Berenguer, 1995: 200). En definitiva, representa la defensa del orden instaurado a través de la violencia en detrimento del diálogo, lo que le hace ocupar parte del sema del rey de Espadas. Esto explica su consideración de que el basto, el jinete y el caballo son la trinidad que puede retener la reforma agraria o de que "el palo y la lengua son ideologías incompatibles". Esta tesis la confirma su aportación a la legislación: "decreto que cada cosa está en su sitio". Quizá, a diferencia de la figura militar de Espadas, Bastos representa uno de los cuerpos paramilitares más significativos del franquismo: la Guardia Civil. Aun así, llama la atención que este personaje esté 
continuamente quejándose de su ciática o tenga un trato tímido con la Princesa en oposición a su defensa de la violencia machista y de la actuación violenta sobre el pueblo. Tal vez sea una forma de individualización que hace más enigmático e impreciso al personaje.

Si volvemos sobre la imagen del tetragramatón formulado por Elda Maria Philips (1984: 102), se puede llegar a la conclusión de que los reyes forman un cuadrado entre sí, pero nunca pueden llegar a ocupar el centro. Así pues, como el Doble en El hombre y la mosca, los reyes no pueden ser la Sota. Esta es, a mi entender, una de las claves de la dramaturgia ruibalesca, puesto que concibe las dictaduras como regímenes personalistas. El sistema se derrumba al desaparecer la figura en torno a la que se crea la dictadura. No obstante, en su presencia, los personajes experimentan una suerte de mimetización que, en el caso de Su Majestad la Sota, se refleja en los cuatros reyes intentando imitar a la Sota para advenirla a su causa. Es más, en una acotación se remarca el apremio con el que actúan los reyes: "rápidamente los reyes se apropian de los gestos de la SOTA. Luego también imitarán su voz". Mucho más compleja es la relación que se establece en El hombre y la mosca en que el Hombre que representa al dictador busca en un largo proceso de entrenamiento cruento la confusión casi sacramental con el Doble, quien debe perpetuar sin fisuras su papel y su sistema político.

A partir de este momento, se produce un proceso de despersonalización de los reyes porque, como el Doble de El hombre y la mosca, están llamados a ser no solo los sucesores del sistema totalitario de la Sota, sino a ser la misma Sota en un signo de inmovilismo absoluto. Como sentencia la Sota, "si los cielos nos son propicios podremos detener el tiempo".

La Sota, por tanto, dentro de ese cuadrado, ocupa el centro y simboliza el poder absoluto, al autócrata, al dictador, en muchas ocasiones en consonancia con el protagonista de la novela latinoamericana de dictador como Yo el supremo, de Augusto Roa Bastos, o El otoño del patriarca, de Gabriel García Márquez. En última instancia, puede asociarse a Franco, probablemente quien motivó la fábula que crea Ruibal, como ya se ha comentado. Su función de personaje latente durante la primera parte de la obra, así como sus medidas intervenciones, potencian el enigma y refuerzan su omnipresencia, porque la Sota "tiene orejas por todas partes".

Esta imagen suele repetirse en las configuraciones alegóricas del poder absoluto del Teatro Underground, como se observa en las piezas de Riaza, Nieva, Romero Esteo o Martínez Mediero. Es más, la extrañeza aumenta cuando la Sota se impone ante las cartas de mayor categoría en la baraja, como los reyes, en una inversión significativa. Por esa razón, Matías, su portavoz, arguye que "cambia de plumaje" 7 porque su palo es secreto de Estado y, según el Periodista 1, "no puede tener hijos", lo que explica la resistencia a morir y las intenciones de perpetuarse "representée par des personnages [como el Hombre

\footnotetext{
${ }^{7}$ En este momento, se producen unos efectos luminotécnicos de gran valor teatral y que refrendan el interés de Ruibal por los aspectos escénicos: "Sobre la Sota giran focos de distintos colores que hacen cambiar la tonalidad de sus ropas".
} 
o la Sota] s'essoufflant à s'auto-proclamer principe et fin de tout" (Reck, 2010: 61). Además, se presenta como un personaje estratega al permitir la intervención internacional, que le beneficia en su lavado de imagen, y al llamar a un árbitro suizo para solucionar el problema de elegir a uno de los cuatro reyes. Un gran momento de lucidez se advierte en su respuesta a la pregunta “QQué hacer cuando la izquierda tiene razón?" que le formula a los reyes, cuya respuesta es "cuando la izquierda tiene razón, lo prudente es dársela... porque pronto dejará de tenerla". Se trata, por tanto, de un modelo de dictador diferente al que suele aparecer en el Teatro Underground que, según Alberto Miralles (1977: 175), tiende a representar la ignorancia de un defensor a ultranza de las armas frente a las letras.

\subsection{El proceso sucesorio en Su Majestad la Sota en relación con el franquismo}

En definitiva, el franquismo y la Sota deciden reservarse la elección de un sucesor monárquico, una estrategia política que se fundamenta precisamente en que, por un lado, “oponemos la eternidad del presente", como dice Matías, en busca de una perpetuación del sistema implantado y, por otro, porque "al cubrir la plaza del rey, meteremos en cintura lo que no existe y todas sus vanas esperanzas", como dice la Sota, reafirmación del régimen totalitario en detrimento de cualquier esperanza contestaria que quiera perturbar la paz y la estabilidad que se atribuyen como proezas tanto el franquismo como el país de la Sota. Así pues, los reyes de la baraja son los candidatos perfectos, igual que un miembro de alguna familia real para la España de los sesenta, ya que "nacimos así [coronados], igual que nacen los gallos con la cresta". La designación de un rey supone una justificación histórica para ambos regímenes que buscan el pasado glorioso y miran atrás guiados por "una continuidad de piedra".

Los candidatos ficcionales son fáciles de enumerar, pero la problemática sucesoria en el franquismo fue uno de los movimientos políticos más arriesgados si se tienen en cuenta las diversas ramas ideológicas: los tecnócratas monárquicos del Opus Dei, la opción regencialista de algunos falangistas, la negativa a la monarquía de otros, la defensa de ceder el trono a un heredero carlista, entre otras. Es más, como señala Ruiz Carnicer (2014: 75):

La aprobación de la Ley Orgánica [elaborada en 1966 y en vigor en 1967] suponía el cierre del diseño del Estado del 18 de julio en previsión de la desaparición física de Franco, pero sin concretar la persona que le sucedería. Franco cerraba la forma del Estado, pero sin nombrar aún sucesor.

Por tanto, el debate sucesorio se centró en los nombres más sonados para aspirar al trono que eran los herederos de Alfonso XIII (don Juan que ocupaba el primer puesto legítimo; su hijo Juan Carlos; don Jaime, que había rechazado en 1933 sus derechos sucesorios por presión paterna; su hijo Alfonso de Borbón Dampierre, que en 1972 se casó con la hija de Franco; o, incluso, José Eugenio de Baviera, sobrino de Alfonso XIII) 
y los herederos según los carlistas (Javier de Borbón Parma y su sucesor Carlos Hugo), que tuvieron posibilidades hasta 1968 que Franco decidió cerrar cualquier cesión al carlismo y nombró a Carlos Hugo como príncipe extranjero, lo que le inhabilitaba para ocupar el trono español (Ramos Fernández, 2014: 197; Barreiro Gordillo, 2018). Por supuesto, tanto para la Sota como para el franquismo, hay un rechazo diametral de la república democrática porque "para nosotros el rey es algo congénito, un poder que emana de la misma naturaleza", lo que parece una alusión a la posición regencialista por la que abogaban especialmente los falangistas reacios a la monarquía.

Sin lugar a duda, el franquismo en la Ley de Sucesión de 1947 se reservó algunas cartas en la manga que dialogan paródicamente con los decretos de la Sota. Así, para optar al trono:

se requerirá ser varón y español, haber cumplido la edad de treinta años, profesar la religión católica, poseer las cualidades necesarias para el desempeño de su alta misión y jurar las Leyes fundamentales, así como lealtad a los principios que informan el Movimiento Nacional (art. $9^{\circ}$, Decreto de 8 de junio de 1947).

Estas condiciones se asemejan, con profunda ironía cómica, al decreto de la Sota que advierte:

PODRÁN CONCURSAR SOLAMENTE PRÍNCIPES VARONES DE CASAS REINANTES. NO SE ADMITEN EXILIADOS POR VIEJOS Y RECALCITRANTES QUE SEAN. EN LO TOCANTE A LA CULTURA ES INDISPENSABLE QUE SEPAN MONTAR A CABALLO.

En cualquier caso, en ambos sistemas, el papel del sucesor queda en un tímido segundo plano porque son "totalmente apolíticos. Seremos el poder moderador. Los representantes legítimos de la monarquía universal", ya que el dictador de facto ostenta todos los poderes (ejecutivo, legislativo y judicial) y está por encima de las leyes que decreta, como por gracia divina. Es más, la relación de Franco con Juan Carlos, como apunta Ramos Fernández (2014: 193), recuerda a la adoptio romana que, en la obra de Ruibal, se trasforma en una contratación de los reyes para formar una Corte que le respalde. Por eso, Matías se apura a negar la existencia de cualquier "candidato putativo", una velada mención a Juan Carlos, criado en el seno familiar de Francisco Franco.

Asimismo, la farsa ruibalesca establece un continuo diálogo con la figura de don Juan, legítimo heredero de la Corona española, y que fue excluido por sus reticencias ideológicas con el régimen, sobre todo tras el Manifiesto de Laussane del 19 de marzo de 1945 en donde abogaba por la monarquía como institución de paz y concordia frente al totalitarismo franquista. Ya en el decreto antes expuesto se explicita que "NO SE ADMITEN EXILIADOS POR VIEJOS Y RECLACITRANTES QUE SEAN", trasunto del artículo decimotercero de la Ley de Sucesión de 1947 que reza: “aquellas personas reales carentes de la capacidad necesaria para gobernar o que, por su desvío notorio de los principios fundamentales del Estado o por sus actos, merezcan perder los derechos de 
sucesión" (Decreto de 8 de junio de 1947); lo que supone una reserva de Franco para elegir a quien gobierna, exactamente igual que la Sota. De ahí las continuas advertencias de Matías que aconseja a los reyes de la baraja que no den por supuesta su validez porque "conozco a muchos tan fastuosos como ustedes que hoy están en el exilio".

Las cartas en forma de leyes que se reservó Franco se convierten en Su Majestad la Sota en cartas literales o, en concreto, en un comodín de "palo ambiguo y sobrenatural, [que] indica que debo proclamarme a mí mismo" porque "no hay fuerza capaz de impedir que me tiña la sangre”. En ese momento, la Sota se adueña de la corona y se la ciñe. Resulta una parodia de innegable correlato con el franquismo, pues en el primer artículo de la Ley de Sucesión de 1947 en la definición de España "de acuerdo con su tradición, se declara constituido en Reino" (Decreto de 8 de junio de 1947) y en el siguiente artículo se señala que la Jefatura de Estado y los derechos sobre la elección del sucesor recaen en Franco, lo que le convierte en dirigente máximo de un reino sin rey en el que él actúa como tal. El ejemplo más significativo de estos poderes está en la decisión de la Sota de conceder el estatus de noble a Matías por su labor que, a semejanza de Franco, concedía títulos nobiliarios y generaba nuevos miembros de la Corte a pesar de ser un derecho exclusivo de reyes: en definitiva, "si yo te acuño, noble serás".

En cuanto al comodín, entendido por Phillips (1984: 102) como "símbolo perfecto de la acomodación política" o como "la ambigüedad pragmática y la astucia maquiavélica" por Zahareas (1997: 27), Ruibal resuelve magistralmente la trama con esta carta de baraja extranjera, puesto que sintetiza la intervención internacional, la justificación para autoproclamarse rey por parte de la Sota, la desestimación de los candidatos para ocupar el poder y su consiguiente integración en las instituciones del régimen. De esta manera, la alegoría funciona como fagocitación de quienes aspiran al poder y su neutralización ante la posible oposición al introducirlos en el sistema, porque señálese que justo antes los reyes plantean el asesinato de la Sota. Además, como advierte el Periodista 1, "con esta carta cualquier plebeyo puede alzarse con el trono". Se refuerza, así, el poder unipersonal en la Sota que, como comentó Ruibal sobre El hombre y la mosca, demuestra cómo "los dictadores suelen eliminar sus competidores, destruyendo así la posibilidad de que su régimen pueda perdurar después de ellos: es una ley de vida" (Siles, 1983: 31). No obstante, en El hombre y la mosca, Ruibal refleja el fracaso esperanzador al morir el dictador, mientras que en Su Majestad la Sota el dictador triunfa. Eso sí, a pesar de haber nombrado a cuatro reyes, ninguno de ellos podrá seguir inamoviblemente su legado.

De esta manera, en una supuesta imparcialidad representada por el árbitro suizo en referencia a las políticas internacionales de neutralidad de Suiza, Ruibal es capaz de sintetizar el camino que seguía el franquismo desde los años cincuenta, preocupado por una nueva imagen de modernidad. Para alcanzar tal fin, según la dramaturgia ruibalesca, el régimen totalitario debe buscar una conciliación con la prensa nacional y conseguir el respaldo más allá de las fronteras; dos caminos que tuvieron su paralelismo histórico: el primero con la controvertida Ley de Presa e Imprenta; y el segundo desde 1953 con el Concordato con la Iglesia Católica y el Pacto de Madrid con EE.UU., continuado en 1955 
con la entrada en la ONU y culminado el proceso en 1959 con la aprobación del Plan de Estabilización por parte del Fondo Monetario Internacional. De esta manera, Ruibal alegoriza perfectamente las claves de un estado totalitario que busca el reconocimiento externo, tema del que probablemente tuvo bastante información al dirigir la sección de política internacional en Arriba.

Ante la aparición del comodín, que cambia definitivamente la acción dramática, los reyes de la baraja reaccionan de manera negativa. Rechazan lo extranjero en sintonía con la actitud del primer franquismo y las políticas autárquicas, en parte derivadas del bloqueo internacional. De esta manera, Su Majestad la Sota se vuelve un ejercicio teatral que plantea de una manera loable y novedosa no solo el proceso de sucesión del régimen franquista, sino el proceso de consolidación del Estado del 18 de julio y el aperturismo, siempre maquillado y premeditado, de los años sesenta.

Por esa misma razón, tras salir el comodín y autocoronarse la Sota como rey, el autócrata, que admite ocupar el trono para evitar regicidios, se apresura a sentenciar que "habrá silencio". Precisamente el silencio compete no solo a la opinión pública o a la población que, como dice el Coro, "estamos contentos / porque nadie / pregunta qué opinamos", sino a aquellos miembros del gobierno que defienden posturas diferentes al dictador. Se confirman, pues, las duras palabras del Coro desde el comienzo de la obra: "La protesta es mentira. / Solo es cierta / la verdad degollada".

En este ambiente de silencio impuesto, el terror generado por las repercusiones limita las acciones reaccionarias e, incluso, supedita los derechos de libertad a las veleidades gubernamentales. Así lo refleja Matías cuando propone detener a los periodistas por "conspirar a favor de un candidato putativo", argumento inventado que sirve de "burda maniobra" para que luego el nuevo rey los libere como signo de avance e indulgencia del sistema. Esta manipulación y arbitrariedad llevan a la necesidad de corresponder a la sabiduría popular: todos "respetamos la ley de las moscas / que no entran en boca cerrada" 8 para que no existan reprimendas. El silencio es, por tanto, un mecanismo de salvaguardia en los totalitarismos.

Así pues, la imposición del silencio se articula como eje del régimen de la Sota que conecta con las palabras del Jefe de Bomberos en El asno (1962), trasunto del poder, que le dice a unos pobres mercaderes: “¿Orden y silencio no son pilares de un mismo estado?

\footnotetext{
${ }^{8}$ La mosca, de evocación sartriana, adquiere una multiplicidad de significados en el imaginario de Ruibal, que ha sido poco estudiado. Por un lado, parece una alegoría de los oprimidos que se ven alienados por el poder absoluto del Estado. Por otro, se presenta como símbolo de la justicia y de la libertad capaz de acabar con el poder. Si Su Majestad la Sota alegoriza sobre la represión y el poder absoluto desde la imposición del silencio a los ciudadanos-moscas sintetizados en el coro, en El hombre y la mosca se indaga cómo ese sistema totalitario es incapaz de perpetuarse porque las dictaduras personalistas no consiguen encontrar "el sucesor de un ser que tan solo con el fulgor de una mirada es capaz de aniquilar todo un rebaño de moscas" (Ruibal, 1977: 56). En el caso de la dictadura franquista, se confirma esta idea al no existir una figura aglutinadora del poder absoluto, sobre todo a partir del atentado de ETA que acabó con la vida de Carrero Blanco en 1973. En torno a esta cuestión, Ruibal comentó: "las moscas van a la carroña. El hombre y la mosca es una obra en donde, al final, todo se cae. Y, cuando se va a caer, las moscas empiezan a rondar. En esta obra hay, por un lado, una mosca que va a la carroña y, por otro, un hombre que pretende matarla y no lo consigue (es el hombre-que-no-mata-una-mosca)" (González Reigosa y Valembois, 1971).
} 
El silencio es una ley magistral. Ahora gobierna en la ciudad" (Ruibal, 1970: 101). De hecho, el silencio va ligado al concepto de paz, que adquiere especial relevancia en esta obra. Cabe suponer, también, que el autor tendría noticias de que en 1964 el régimen preparó la celebración de los Veinticinco Años de Paz tras el triunfo de los sublevados en la Guerra Civil española. Por ello, como le aconseja Matías a un periodista al comienzo de la obra, "goce de la paz que aquí se cosecha. No se da con más silencio en todo el mundo".

Tras todo este tratado dramático de las dictaduras, tan solo falta en Su Majestad la Sota la constatación del triunfo del dictador, puesto que tanto el dictador ficticio como el real se agencian la creación de un Estado ad hoc, según sus veleidades y necesidades y, a pesar de nombrarse un rey, continúan gobernando y acumulando todo el poder en su propia persona. Este proceso celebratorio final se concibe de una manera significativa en la dramaturgia de Ruibal: se festeja un esperpéntico tute de reyes en que, al primer rasgueo de la guitarra de la Sota, los monarcas "automáticamente, comienzan a menearse en sus cartas" frente al Coro que "vuelve al ritmo traumático del comienzo". El tute es un juego que consiste en reunir los cuatro reyes o caballos para ganar, con lo que el dramaturgo continúa con la polisemia en relación con las cartas. De esta manera, los reyes se convierten en el tute político al son de la Sota.

Esta propuesta escénica final confirma que Su Majestad la Sota se puede definir como un "drama que a cada paso se proyecta como espectáculo de actividades, escenarios, tiempos, personajes y motivos amarionetados" (Zahareas, 1997: 27). Además, se evoca, en cierta medida, las Danzas de la Muerte en que la figura de la Muerte toca una música que bailan todos los muertos independientemente de su condición terrenal y que conecta con estos cuatro reyes sometidos a la inversión de la jerarquía de la Sota. A manera de mojiganga contemporánea, se sintetiza el triunfo del poder absoluto que maneja a todos los integrantes de su sistema político. Es más, esta escena conecta con otra suerte de mojiganga ruibalesca, que funciona también como "défilé triomphal" (Reck, 2010: 76), incluida en El hombre y la mosca, denominada "Marcha de las calaveras", que remite a Las visiones de la muerte calderoniana, cuya función en la trama consiste en la toma de consciencia de la muerte y la celebración del triunfo del Hombre (trasunto del dictador) sobre los tercos (trasunto de los republicanos).

\section{CONCLUSIONES}

Como se ha analizado sucintamente, el entramado alegórico de José Ruibal en torno a la baraja española se caracteriza por una profunda complejidad semiótica. Si bien la obra llega a una autoconsciencia lingüística loable en donde la baraja se resignifica y las alegorías reciben una multiplicidad de significados, lo cierto es que puede devenir en una obra confusa, críptica y distanciada para el espectador. No obstante, los mecanismos de abstracción de Ruibal muestran aún cierta vigencia y, aunque se haya hecho una lectura 
desde sus relaciones con las políticas franquistas, llama la atención cómo perduran ciertos estereotipos asociados al poder y ciertas imágenes que el dramaturgo activó en esta obra.

Aunque no ha sido asunto de nuestro análisis, Su Majestad la Sota se formula de esta manera debido al camino que comenzó a explorar la dramaturgia ruibalesca a mediados de los años sesenta. En este periodo de escritura, Ruibal decidió adentrarse aún más en el arte teatral en sí: potencia el simbolismo y elabora espacios y personajes alegóricos de mayor complejidad alejados del aire naif de obras como La ciencia de birlibirloque o El asno; profundiza en la concepción del espacio dramático y sonoro y los integra de forma significativa en el conjunto de la obra, por eso, la escenografía de Su Majestad y la Sota augura los proyectos escenográficos de envergadura que se reflejan en El hombre y la mosca y, sobre todo, en La máquina de pedir; y, además, refina el humor, la distancia paródica y la ironía al mezclarlos con la polisemia, por lo que no solo se refleja a nivel lingüístico, sino en la trama y las acciones de los personajes.

El humor permite, en la producción ruibalesca, la distanciación con la cruenta realidad que explora el dramaturgo, que entremezcla las propuestas de Brecht, Artaud o ValleInclán. En Su Majestad la Sota, también se puede observar cómo Ruibal explora este distanciamiento a la vez que afronta de una manera más madura los temas que más le preocuparon en la escritura: el capitalismo, el poder absoluto y su perpetuación, la desnaturalización y mecanización de la vida, la libertad de prensa, la sexualización de la mujer, la desigualdad o la pobreza. Y formula, así, una suerte de tratado de política del siglo XX en un tono festivo en donde el dramaturgo irrisoriamente se pregunta: "¿esto qué es, un moderno estado o una catacumba abandonada?". Por tanto, Ruibal presenta una distancia irónica motivada por la parodia que termina por articularse como una reflexión triunfalista y pesimista sobre la sucesión del totalitarismo que se opone diametralmente al carácter trágico y ritual de El hombre y la mosca que, contra todo pronóstico, acaba en una lectura esperanzadora.

Pero la gran aportación de esta pieza, más allá de ser una obra de transición hacia una dramaturgia de madurez, a mi modo de ver, reside en la capacidad de Ruibal para construir un entramado alegórico tan evocador. Se palpa la erudición política y las vivencias del autor que parece llegar a la misma conclusión que José Pemartín en Los orígenes del movimiento (1938): "el Caudillo hace la Historia, pero el Rey es la Historia" (Cerdà Serrano, 2015: 100). De esta manera, Ruibal sintetiza en Su Majestad la Sota su visión de los procesos de perpetuación de las dictaduras, en donde una Sota es capaz de poner a bailar a cuatro reyes de la baraja española. 


\section{REFERENCIAS BIBLIOGRÁFICAS}

ANÓNIMO (1970). "III Congreso Nacional de Teatro Nuevo". Yorick 40, 48-49.

BARREIRo Gordillo, C. (2018). "La designación de don Juan Carlos vista por los diarios madrileños: una perspectiva comparada". Pasado y Memoria. Revista de Historia Contemporánea 17, 479-506.

Berenguer, Á. (1995). “José Ruibal y la tradición del Teatro de Resistencia”. En Teatro español contemporáneo. Autores y tendencias, A. de Toro y W. Floeck (eds.), 191-216. Kassel: Reichenberger.

Cerdà Serrano, J. (2015). "Historicismo y legalismo en los discursos franquitas sobre la monarquía española. La Ley de Sucesión en la Jefatura del Estado de 1947”. Revista Jurídica Universidad Autónoma de Madrid 32, 99-126.

CORNAGO, Ó. (2005). "La teatralidad como paradigma de la Modernidad: una perspectiva de análisis comparado de los sistemas estéticos en el siglo XX”. Hispanic Research Journal 6.2, 155-170.

DECRETO de 8 de junio de 1947 por el que se somete a referéndum de la Nación el Proyecto de Ley aprobado por las Cortes Españolas, que fija las normas para la Sucesión en la Jefatura del Estado, Boletín Oficial de España. Disponible en línea: https://www.boe.es/datos/pdfs/BOE/1947/160/A03272-03273.pdf [30/12/2019].

DíEz, L. A. (1983). "El estreno mundial en New York de El hombre y la mosca. José Ruibal frente al secreto encanto de la dictadura". Pipirijaina 24, 34-37.

Feuillastre, A. L. (2016a). "Las obras perdidas del Nuevo Teatro: hallazgo y recuperación de una vanguardia silenciada". Philobiblion: Revista de Literaturas Hispánicas 3, 39-52. Disponible en línea: http://www.joveneshispanistas.com/wpcontent/uploads/2016/05/1x03-Philobiblion_Anne-Laure.pdf [15/12/2019].

(2016b). "La ficción de poder en el teatro vanguardista de José Ruibal al principio de la Transición". En La transición sentimental: literatura y cultura en España desde los años 70, M. A. Naval López y Z. Carandell (coords.), 145-158. Madrid: Visor Libros.

Gómez GARCíA, M. (1971). “1971: Así piensan 40 profesionales de nuestra escena sobre censura, teatro social y teatro político en España”. Primer Acto 131, 8-24.

GonZÁlez Reigosa, C. Y VAlembois, V. (1971). “Entrevista a José Ruibal”. Ínsula 298, 4.

Miralles, A. (1977). Nuevo teatro español: una alternativa social. Madrid: Villalar.

MuÑoz CÁliz, B. (2006). Expedientes de la censura teatral franquista. Madrid: Fundación Universitaria Española.

Oliva, C. (1989). El teatro desde 1936. Madrid: Alhambra.

ORDEN de 9 de febrero de 1963 por la que se aprueban las "Normas de censura cinematográficas", Boletín Oficial de España. Disponible en línea: https://www.boe.es/boe/dias/1963/03/08/pdfs/A03929-03930.pdf [15/12/2019].

PhILLIPS, E. M. (1984). Idea, signo y mito: el teatro de José Ruibal. Madrid: Orígenes. 
RAMOS FERNÁNDEZ, L. F. (2014). Las limitaciones a la Libertad de Expresión, derivadas de la reinstauración de la Monarquía en España. A Coruña: Universidade da Coruña.

RECK, I. (2010). Nuevo teatro español (1965-1978). De l'enchantement textuel au désenchantement. Francisco Nieva, Luis Riaza, Miguel Romero Esteo, Antonio Martínez Ballesteros. Strasbourg: Presses Universitaires de Strasbourg.

RuiBAL, J. (1970). La máquina de pedir. El asno. La ciencia de birlibirloque. México: Siglo XXI.

(1977). "José Ruibal". En Teatro español actual, AA. VV., 257-264. Madrid: Fundación Juan March / Cátedra.

Ruiz CARNICER, M. A. (2014). "Fascistas de izquierdas en los años sesenta. La búsqueda de las bases populares para el proyecto de una izquierda nacional en la España de Franco". Rubrica Contemporanea 3.5, 71-87.

Ruiz RAMÓn, R. (1986). Historia del teatro español. Siglo XX. Madrid: Cátedra.

SAmAniEgO, F. (1977). "José Ruibal estrenará su obra El hombre y la mosca. Estaba retenida por la censura desde 1968". El País, 11 de febrero.

Siles, L. E. (1983). “José Ruibal: recuperar la tradición española”. Pipirijaina 24, 30-33.

VAN Der NAALD, A. C. (1981). Nuevas tendencias en el teatro español. Matilla-NievaRuibal. Miami: Universal.

Wellwarth, G. E. (1970). “Teatro español de vanguardia”. Primer Acto 119, 50-58.

ZAHAREAS, A. N. (1997). "Espectáculo de muñecos: realidad y metáfora". Hispánica XX $15,23-42$.

Fecha de recepción: 15/01/2021

Fecha de aceptación: 26/06/2021 